long-run, successfully withstand such a big military power as Russia. Assuming that Austria could be relied upon, it is possible that Russia might attempt the invasion of Turkey with a force of some two or three hundred thousand men; proceeding, let us suppose, through Roumania to the Danube, and utilising the line of rail passing from Odessa to Kischeneff, vid Jassy, to Bucharest and Giurgevo. In that case it seems to us, judging from the experience gained in some late wars, that there would be extreme difficulty in transporting the troops to the front, and the sick and wounded to the rear. The two great natural obstacles in the path of the Russians would be the Danube and the Balkans, and, if the Turks retained command of the sea, Varna would be for them a most important position.

Apart, however, from all military difficulties, there are very grave ones on the score of climate and disease. Very much will of course depend upon the charactex of the season, upon the duration of the campaign, and its successful progress, but it must never be forgotten that the valleys of the Danube and its tributaries are the homes of endemic diseases, of malarious diseases, agues, dysentery, and severe and exhausting fevers; and that in the medical history of all the campaigns against the Ottoman power, disease has played a formidable part. Bulgaria is not so marshy near the Danube as Roumania. The climate of Roumania may, on the whole, be regarded as good, but it is subject to extreme changes of temperature-hot by day, and cold at night-and it is owing to these alternations, together with the miasma arising from the swamps in the vicinity of the Danube and its affluents, that pernicious aguish fevers are prevalent. It is scarcely probable that an army in the field would escape without much inefficiency from sickness-such as fevers, diarrhoea, and dysentery, possibly cholera, to which other diseases might be superadded or not, according to the nature and adequacy of all the preparations and arrangements, or the reverse. The success of an expedition will greatly hinge on supplies of good diet, sufficient clothing to protect against nocturnal cold, and a rapid advance. The Russians in 1828 suffered terribly from disease, and the losses among our own troops at Varna immediately before the Crimean war, from cholera, diarrhcea, and fever, were considerable. In a paper read by Dr. J. J. Woodward, U.S.A., at the International Medical Congress of the Philadelphia Exhibition of 1876, on Typho-malarial Fever, the author has with much care and erudition collected, from the experience of previous campaigns, a number of facts pertinent to the subject under consideration. There was the socalled Hungarian fever which for three centuries played so formidable a part in the campaigns undertaken by the House of Austria against the Turks-a fever of so fatal a character as to occasion the proverb that "Hungary is the grave of the Germans." This is now generally admitted to have been a hybrid between the remittent fevers endemic to the soil and typhus. In 1566 the soldiers of Maximilian II. returning to their homes spread typhus fever far and wide; and before this, in 1542, a fever broke out in the camp before Ofen in the Imperial German army that had been led against the Turks, which was said to have killed 30,000 men in the subsequent disastrous retreat. The epidemic of $\mathbf{1 5 6 6}$ is described by Thomas Jordan, who accompanied the army of Maximilian as his chief medical officer. The spring had been exceedingly wet, the great Hungarian streams had overflowed their banks; the summer following was unusually hot, and the Germans were badly supplied with food. The fever first appeared while the army was encamped at Komorn, at the point of junction of the Waag and the Danube-a marshy malarial plain. In the camp at Raab, where the Raab and Rabnitz empty into the Danube, it became still more destructive. Although the force of Maximilian at Raab camp was about 80,000 men, he was unable to take the offensive against the Turks, and in early autumn had to retreat with the remains of his army. In 1597, in 1661, and again in 1717, in the army with which Prince Eugene besieged Belgrade, when the Prince's force was shut up in the marshy plain between the Danube and the Save, this Hungarian fever broke out accompanied by dysentery. In 1788 the campaign which the Emperor Joseph II. undertook against the Turks proved a disaster from similar causes. Although this fever was probably mainly typhus or relapsing fever, still the observers of that day believed with much reason that the malarious fever which occurs every year in Hungary, the valley of the Danube, and Southern Russia, and attains malignity only in epidemic years, was an important factor Side by side with the Hungarian fever there appeared among the German soldiers another disease of more chronic character, known as Languor Pannonicus, and compounded apparently of malaria and scurvy. Dr. Woodward, curiously enough, hazards the prophecy that when an army again goes into the valley of the Danube, the old Hungarian plagues will re-appear, and prove a more formidable foe to be encountered than the Turk.

As might be expected, Russia is in a position very supe. rior to Turkey as far as the organisation of the medical service, hospital materiel, and transport are concerned; for as far as we can learn, the Turks have a medical organisa tion that, like their "constitution," looks admirable on paper, but the efficacy of both has yet to be tested by their application.

It is excessively unlikely that there will be any recurrence on a large scale of such diseases as are indubitably traceable to the total ignorance of the laws of health and an utter neglect of any hygiene that characterised past days, but that an expedition against the Turks on a large scale-and it must be on a large scale to be successful-would prove a difficult, dangerous, and expensive undertaking we have no doubt.

\section{ON THE RELIEF OF PAIN BY THE OUTWARD APPLICATION OF HYDRATE OF CHLORAL.}

To the Editor of THE LANCET.

SrR,-I am desirous to assist in bringing under the notice of the profession the benefit to be derived in the relief of pain by the external application of hydrate of chloral, for the knowledge of which I am indebted to my friend Dr.T. S. Dowse, of the Central London Sick Asylum, Highgate. The vast field that is afforded by these metropolitan instio tutions for the cultivation of practical medicine is not neglected by Dr. Dowse, but is turned by him to good account. The results of the trial of hydrate of chloral as an external application have lately been given. I would beg permission to add my experience of this mode of using this drug, in order that it may become more widely known.

I have tried it with great success in neuralgic pains and in cancer of the breast, in cases in which other sedatives and narcotics have failed to give relief.

The mode of application is by the saturation of folds of lint of the size of the part to which it is to be used, bronght into close contact, then covered with three or four layers of lint covered with oil-silk or spongio.piline wrung out of hot water. The application to raw surfaces, of course, requires some care in manipulation.

The strength of the solution is about four drachms to sis. teen ounces of water. The addition of a small quantity of glycerine is advantageous. Chloride of zinc or perchloride of iron can be combined with the chloral in certain cases. I remain, Sir, your obedient servant,

Holloway, N.

W. B. KESTEVEN, M.D. 